\title{
Aerodynamic Performance of the Flapping Wing
}

\author{
Abbas Ebrahimi and Karim Mazaheri \\ Aerospace Systems Center of Excellence, \\ Sharif University of Technology \\ Iran
}

\section{Introduction}

Flapping is described as simultaneous heave and pitch oscillations of a wing. The dominant way for producing lifting and propulsive force in natural flight is flapping (Pennycuick, 2008; Shyy et al., 1999). Unlike the most common aerial vehicles, in flapping flight, both lift and thrust forces are produced simultaneously by flapping wings. Apparently, flapping is an efficient way for flight in low Reynolds numbers. Currently, the field of low Reynolds number aerodynamics is receiving considerable attention because of a global recent interest in development of Micro Air Vehicles (Shyy et al., 2008).

However, the aerodynamics of flapping flight is not fully understood at present and for the same reason, no design method for flapping wings is readily available (Shyy et al., 1999). Both experimental works (Murphy, 2008; Wilson \& Wereley, 2007; Hong \& Altman, 2007; Isaac et al., 2006; Muniappan et al., 2005; Ames, 2001) and numerical studies (Mantia \& Dabnichki, 2009; Fritz \& Long, 2004; Ho, 2003; Jones et al., 2002; Smith et al., 1996; Vest \& Katz, 1996) are carried out in this field to explore more about the complex aerodynamic phenomena occurring during the flapping flight. The experimental works include quantitative studies like measuring the forces and moments on a flapping wing in a wind tunnel and qualitative studies such as visualizing the flow in the wakes behind a flapping wing. Although the findings of these studies generate deep insight into the flow structure around flapping wings, this information is generally very qualitative and there is no straight way to use this information for designing flapping wing vehicles.

Ref. (Lasek \& Sibliski, 2003) describes the nonlinear modeling of the six degrees of freedom motion of a flapping wing Micro Aerial Vehicle in a turbulent atmosphere. Gebert and Gallmeier (2002) also have investigated the dynamic equations of the motion of flapping wing vehicles. They have found a system of equations, but they have not analyzed these equations to see the effects of different parameters on overall flight characteristics, or on temporal flight dynamics. In (Willis et al., 2006), computational schemes are used to optimize the flight power of a flapping wing. The parameters considered there are: the flapping frequency, the flapping amplitude, and the addition of a mid-wing hinge for articulated flapping flight. The flight power coefficient is minimized for specified flight conditions over a restricted set of flapping parameters. 
In Gallivan and DeLaurier (2007), an experimental aerodynamic performance investigation was done on a single set flapping membrane wings with different wings aspect ratio, weight, spar rigidity and batten tailoring. Aditya and Malolan (2007) showed that the Strouhal number affects the propulsive thrust force of a flapping wing. The optimum value is corresponding to a narrow range of Strouhal numbers, which is recommended to be used by wing designers. Lin et al. (2006) also measured the aerodynamic forces for a flexible membrane flapping wing for different flapping wing frequencies, angles of incidence and wind speeds. They observed that the lift force will increase with the increase of the flapping frequency under the corresponding flying speed, while a decrease in the angle of incidence in the same flapping frequency will result in flying speed increase, and a slight decrease in the lift force.

In (Kim et al., 2008), the aerodynamic characteristics due to the effects of the camber and the chordwise wing flexibility were investigated. The experimental results demonstrate that the effect of the camber generated by the macro-fiber composite (MFC) produces sufficient aerodynamic benefit. The chordwise wing flexibility is one of the important parameters affecting to the aerodynamic performance, and can help the wing to stabilize the small leading edge vortex in the unsteady flow condition.

In another experimental investigation, Pfeiffer et al. (2010) proposed the time-efficient integrative simulation framework for the trimmed longitudinal flight of model ornithopter based on the flexible multi-body dynamics and considering fluid-structure interaction. They observed a limit-cycle-oscillation of flight state variables, such as pitch attitude, altitude, flight speed, during the trimmed flight of the model ornithopter. The concept of the "zero moment point" is introduced to explain the physics of ornithopter trimmed longitudinal flight.

In (Mazaheri \& Ebrahimi, 2010a), we have experimentally studied the effect of the flexibility on the aerodynamics of flapping wings. The objective of this research is to provide further insight into the flight performance of flapping wing vehicles. The flight envelopes and design curves of flapping wing vehicles are not well developed yet. Our main target here is to formulate a performance analysis procedure for a flapping wing, based on its wing experimental aerodynamic data. A mechanical flapping system capable of producing flapping motion for a special flexible membrane wing is designed and built. The aerodynamic performance of the fabricated wing is experimentally studied through time varying lift and thrust measurements. This experimental work is conducted in a large, lowspeed wind tunnel. Results are plotted with respect to the flapping frequency, wind tunnel velocity and angle of incidence. These results are used here to optimize the design of a flapping machine. To do this, we have introduced two flight performance criteria, and have presented a new algorithm to use aerodynamic information to optimize flight conditions according to these criteria. On the basis of this, one finds the optimum value of angle of incidence and flapping frequency based on vehicle weight and speed.

\section{Aerodynamic parameters}

Here we are going to model the aerodynamic performance of a flapping wing, which may allow us to optimize its design and performance. This may be used at the same time as a design method for design of flapping wing vehicles for different applications or missions. 
Let us assume that lift $(L)$ and thrust $(T)$ forces are functions of flapping frequency $(f)$, the wind speed $(V)$, the angle of attack $(\alpha)$, kinematic viscosity of air $(v)$, mean chord $(c)$, and the wing design:

$$
\begin{aligned}
& L=F(f, V, \alpha, v, c, \text { wing shape }) \\
& T=F(f, V, \alpha, v, c, \text { wing shape })
\end{aligned}
$$

Note that for our application, viscosity of air is almost constant. The flapping vehicle weight $(W)$ depends on mission, and in cruise flight it is equal to the average lift force $(L=W)$. Generally, flapping vehicles experience acceleration or deceleration, but for steady state flight (cruise flight condition), the average force in the flow direction (i.e. thrust minus drag) is zero $(T=0)$, and the wind speed is equal to the cruise velocity $(V=U)$. Note that the aerodynamic force in the flow-direction depends on the drag force of the body and the wing itself, and the thrust force generated by the wing. In our analysis, we could not distinguish between the drag and thrust force of the wing, and we could measure or compute the total thrust force, as combination of these two. This is the force that we measure in the wind tunnel. Basically, in flapping vehicles it is not meaningful to distinguish between these two forces. With the above two constraints and using relations (1) and (2), we may find the cruise speed for a given wing design as:

$$
\left.\begin{array}{c}
L=W=F(f, V, \alpha) \\
T=0 \Rightarrow V=U=F(f, \alpha)
\end{array}\right\} \Rightarrow V=U=F(f, \alpha, L=W)
$$

For each flapping frequency and angle of incidence, there is either no or one stable cruise velocity. Similarly, for each cruise speed and flapping frequency, there is at most only one stable angle of incidence.

\section{Flapping mechanism and flexible membrane wing}

The propulsion system of a flapping wing aircraft consists of different components including a battery, an electric motor, a gearbox, a flapping mechanism, and flexible wings. The flapping wing mechanism is adapted from a Cybird P1 remotely controlled ornithopter (Kim et al., 2003). Figure 1 shows the flapping mechanism and the range of operating angles of the flapping mechanism. The design parameters of flapping mechanism and the analytical results of its kinematics were presented in (Mazaheri \& Ebrahimi, 2010b). This simple four-bar crank rocker mechanism transforms the rotational motion of a small electric motor to a harmonic flapping motion. One flapping wing period can be divided into: upstroke and downstroke. The flapping frequency is controlled directly by altering the input voltage. The follower link oscillates between $+29^{\circ}$ and $-21^{\circ}$ from the horizontal line. Figure 2 shows analytical results for angular displacement and the corresponding velocity and acceleration of the follower link versus time, for a full period of flapping. During the test, the flapping mechanism is capable of flapping its wing at a maximum frequency of 10 $\mathrm{Hz}$.

Design and development of an efficient wing is the most significant requirement towards making a flapping wing vehicle. Although many researchers have noted that flexible wings 
play an important role in the aerodynamics of flapping flight, there exist few, although important, studies dealing with flexible rather than rigid wings in flapping flight (Isogai \& Harino, 2007; Wu et al., 2008; Singh, 2006; Smith, 1996; Daniel \& Combes, 2002).

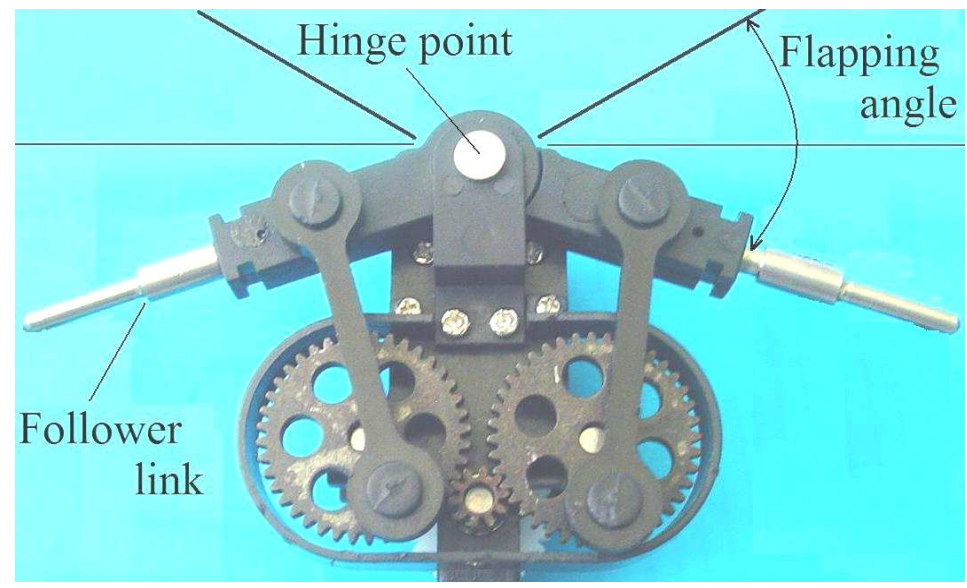

Fig. 1. The flapping wing mechanism

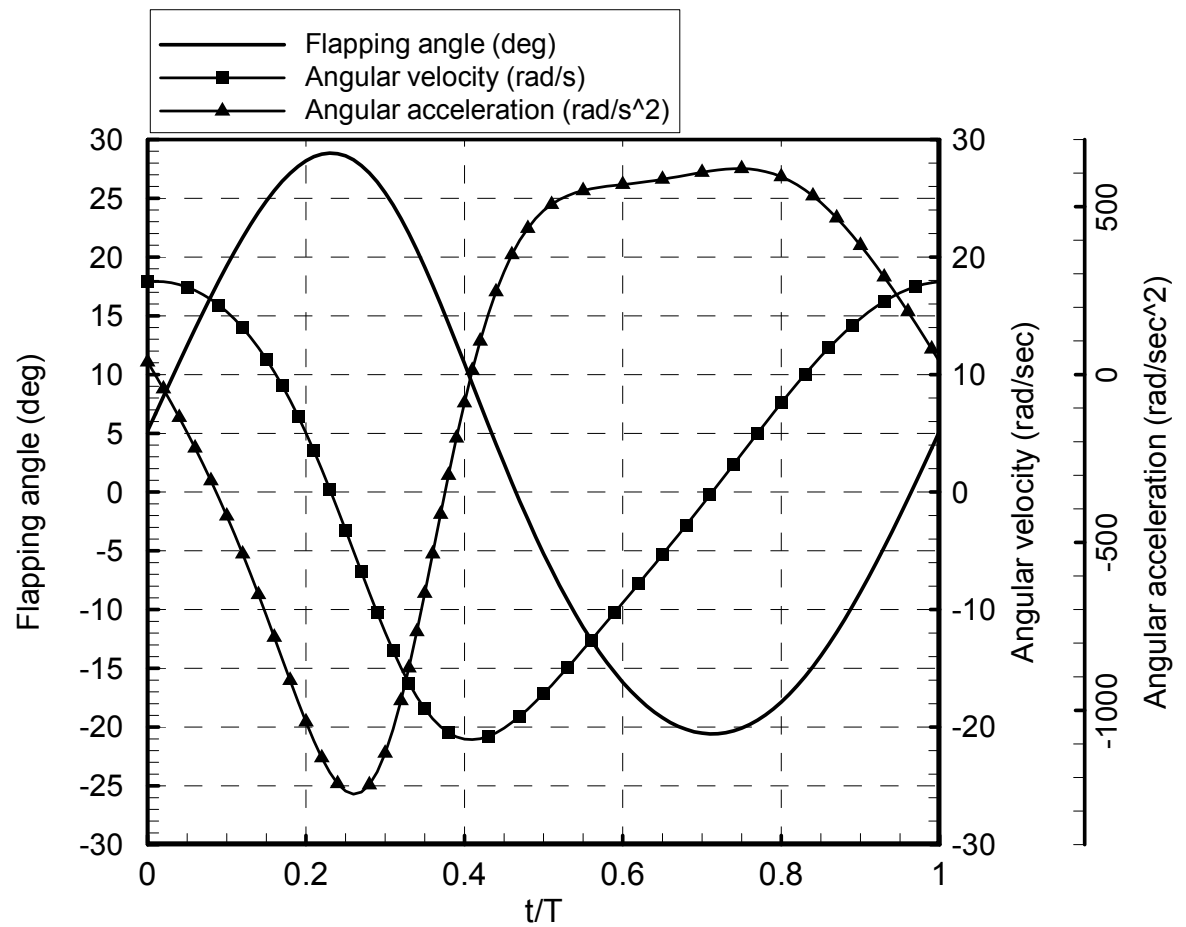

Fig. 2. Flapping angle, angular flapping velocity and angular flapping acceleration for one complete cycle (7 Hz frequency) 
It is vital that the aeroelastic similarity parameters be the same for two wings, to have similar aerodynamic performance. The main parameters affecting aeroelastic performance are mass and stiffness distribution.

Figure 3 shows the structure and a planform view of the flexible membrane wing developed here. The wing has a roughly half-elliptical planform with a span of $0.8 \mathrm{~m}$, mean chord of $0.14 \mathrm{~m}$, single wing area of $0.047 \mathrm{~m}^{2}$, mass of 14.4 grams and an aspect ratio of 6.8 . The main parts of the wing are the spar, the ribs and the skin. The wing's cover is made of nylon sheet and is stiffened by carbon-fiber ribs. As the main spar, one rib makes up the leading edge of the wing, while three other ribs run in the chord direction. The main spar and ribs virtually provide the wing's stiffness. The dynamic bending and twisting of the wing determine the generated lift and thrust. The root of wing's leading edge is rigidly attached to the follower link of the flapping mechanism (see Fig. 1 and 3).

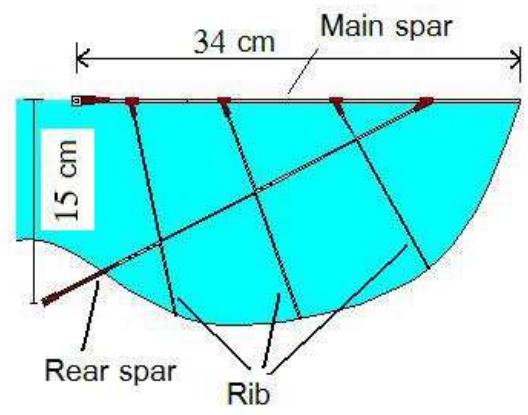

Fig. 3. A planform view of the flexible membrane wing shape schematic

\section{Experimental set-up}

A test bed, as shown in Fig. 4, is built to investigate the aerodynamic performance of a flapping wing vehicle. To simulate the effects of forward flight, a large closed-loop, lowspeed, open test section wind tunnel with a test section of $2.8 \mathrm{~m} \times 2.2 \mathrm{~m}$ and maximum speed of $48 \mathrm{~m} / \mathrm{sec}$ is used. The velocity nonuniformity in the test section is less than $0.2 \%$ and the turbulence intensity in the center of the test section is less than $0.13 \%$. To avoid wall interference effects, we have used an open test section wind tunnel. Figure 5 shows a view of the test bed and the mechanism in the open test section of the wind tunnel.

Unsteady lift and thrust forces are measured using a one-dimensional load cell. The load cell is calibrated statically using known weights and the measured calibration factors are used to convert the gauge voltage signals to forces. For the load cell, the measurement in the range up to 1000 gram shows that the relative error is below $0.5 \%$. Hysteresis, nonrepeatability and nonlinearity of this sensor are below $0.1 \%$. The natural frequency of this sensor $(280 \mathrm{~Hz})$ is well above our flapping frequencies. The load cell is installed in the correct direction to measure horizontal and vertical forces respectively. Note that the angle of incidence is measured as the angle between body horizontal axis and the flow direction (Fig. 5) and also, there is $2^{\circ}$ positive angle between the flapping axis and the body horizontal axis. The signals received from the strain gauges are amplified electronically using an amplifier before being sampled at $1000 \mathrm{~Hz}$. To measure the wing's power usage, a current measuring unit is 
designed to use the CSNE151-100 closed loop current sensor. The current sensor is appropriate for variable speed drives and measures AC or DC current with $0.5 \%$ accuracy.

All signals are acquired using a data-acquisition board. Then, the data are filtered in an online process using a $3^{\text {rd }}$ order low-pass digital Butterworth filter with a cutoff frequency of about $15 \mathrm{~Hz}$. This cutoff frequency will filter the high-frequency noises generated by motor jitter or vibration of other components. The first natural frequency of the wing is much higher than the flapping frequencies considered here.

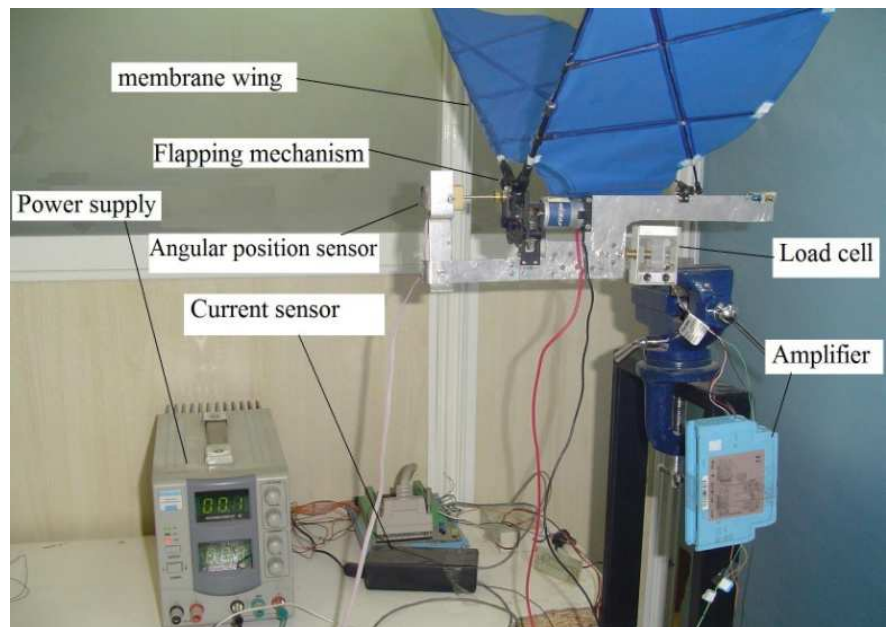

Fig. 4. Experimental set-up

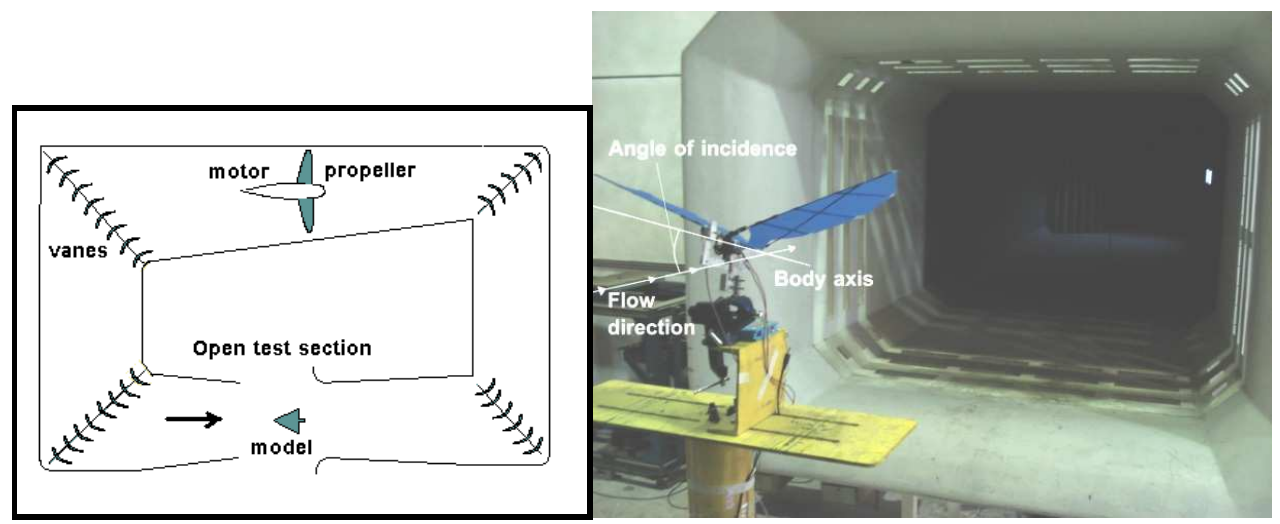

Fig. 5. Flapping wing system in open test section wind tunnel

\section{Results and discoussion}

\subsection{Modeling experimental aerodynamic parameters}

Tests were conducted at four different free-stream velocities, between 6 and $12 \mathrm{~m} / \mathrm{s}$. For each free-stream velocity, flapping frequency has been varied from zero to $9 \mathrm{~Hz}$. The 
experiments were repeated for different angles of incidence (zero to $20^{\circ}$ ). The generated lift, and thrust, and the power consumption are measured in each different case $\left(T=F\left(f ; V, \alpha=\alpha_{i}\right)\right.$ and $\left.L=F\left(f ; V, \alpha=\alpha_{i}\right)\right)$. Most graphs presented here show the time average of the measured data, based on more than ten cycles.

The average thrust (i.e. thrust minus drag) and lift variation for different free-stream velocities, flapping frequencies and $10^{\circ}$ angle of incidence are plotted in Fig. 6. Increase in flapping frequency always result in higher propulsive force. At the same time, increase of wind speed, as expected, results in lower propulsive force (due to increase in drag forces). The general trends of thrust force do not change in different angles of incidence. Also, there is almost no change in lift for low flapping frequencies (up to $5 \mathrm{~Hz}$ ), but it increases for higher flapping frequencies proportional to the flapping frequency. The wind speed also always increases the lift force. The general trends of lift force are similar for another angles of incidence, and that for higher flapping frequencies, the increase rate of lift due to flapping frequency is higher for lower angles of incidence.

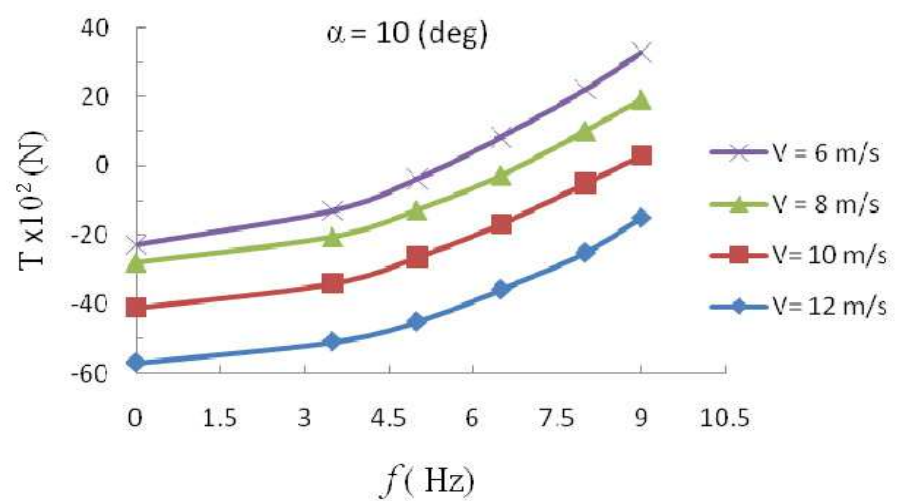

(a)

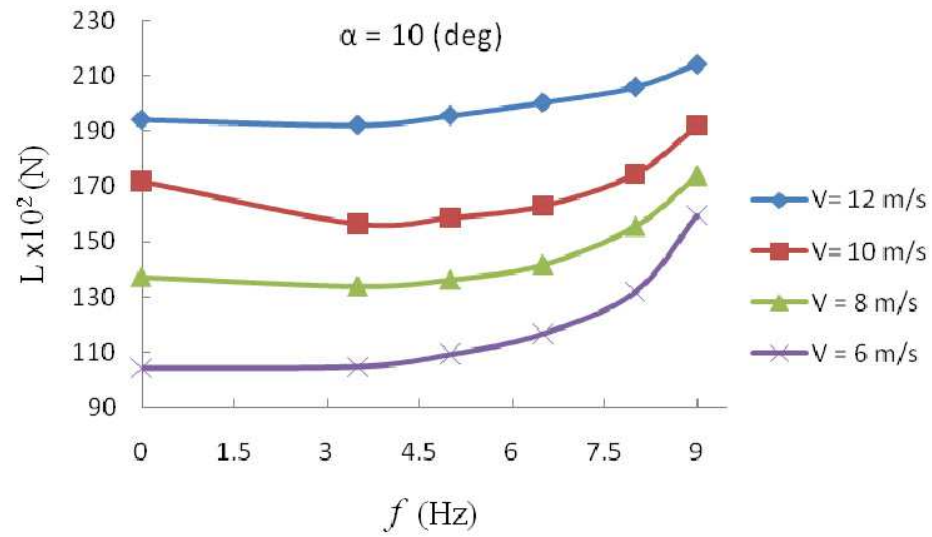

(b)

Fig. 6 . The average thrust and lift force versus flapping frequencies for different wind speeds and $\alpha=10^{\circ}$ 


\subsection{Formulation of flight envelopes}

Flight envelopes and design curves are not considered and analyzed by researchers active in this field. Here, we formulate a new scheme to find flight envelopes for a particular flapping wing vehicle. This algorithm is stated in four steps below. The main performance parameter is the possible cruise speed. Since power consumption is basically a function of frequency, for each given weight and payload, one may find the best cruise speed for maximum range, which is corresponding to minimum ratio of power to cruise speed $\left(\frac{P}{U}\right)$ (i.e., energy usage for unit distance), or for maximum endurance corresponding to minimum power (i.e., minimum flapping frequency).

1. Imposing the no-thrust constraint $(T=0)$ for each angle of incidence, using Fig. 6a, $T=F\left(f ; V, \alpha=\alpha_{i}\right)$, one finds possible cruise speed for each flapping frequency, $U=F\left(f ; \alpha=\alpha_{i}, T=0\right)$. Results for cruise speed as a function of the flapping frequency, for various angles of incidence are shown in Fig. 7. Also the power consumption at different flapping frequencies (cruise flight velocities) and angles of incidence (i.e. $P=F\left(f ; \alpha=\alpha_{i}, T=0\right)$ and $\left.P=f\left(U ; \alpha=\alpha_{i}, T=0\right)\right)$ could be derived as shown in Fig. 8 . Similarly, one may produce ratio of power to cruise speed criteria, $\frac{P}{U}=F\left(f ; \alpha=\alpha_{i}, T=0\right)$. These results are shown in Fig. 9. We will use this diagram later to find optimum conditions for the best possible range for each given vehicle weight.

2. Use Fig. $6 \mathrm{~b}, L=F\left(f ; V, \alpha=\alpha_{i}\right)$, to find the lift force for cruise. For this cruise flight, the average lift force coefficient as a function of the flapping frequency for various angles of incidence, $L=F\left(f ; \alpha=\alpha_{i}, T=0\right)$, and various flight speeds, $L=F\left(f ; U=U_{i}, T=0\right)$, is shown in a carpet plot in Fig. 10.

3. Now for a given vehicle weight $\left(L=W_{i}=0.15 \mathrm{~kg}\right.$ ), one may use Figs. 7 and 10 to draw cruise speed versus flapping frequency, $U=F\left(f ; L=W_{i}\right)$. These results are shown in Figs. 11a and $11 \mathrm{~b}$, and values of $P, \alpha$, and $\frac{P}{U}$ are indicated at each point. Similarly, one may use Figs. 7 and 10 to find angle of incidence versus flapping frequency, $\alpha=F\left(f ; L=W_{i}\right)$. Figures $12 \mathrm{a}$ and $12 \mathrm{~b}$ show the results, and the values of $P, \alpha$, and $\frac{P}{U}$ are indicated at each point.

4. For each point in Figs. 11a and 11b or in Figs. 12a and 12b, one may find values of $P, \alpha$ and $\frac{P}{U}$ and draw two different graphs:

a. The flight power curve, $P=F\left(f ; L=W_{i}\right)$, which helps us to find the maximum endurance conditions for a given vehicle weight.

b. The flight power to cruise speed curve, $\frac{P}{U}=F\left(f ; L=W_{i}\right)$, which helps to find the maximum range conditions for a given vehicle weight. 


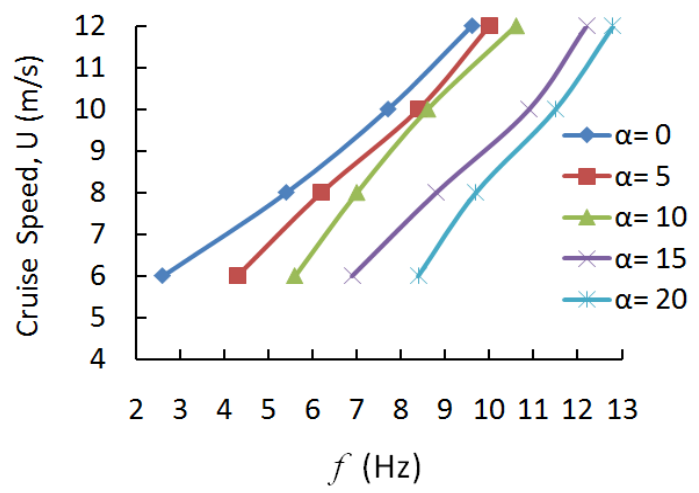

Fig. 7. Cruise speed as a function of the flapping frequency, for various angles of incidence

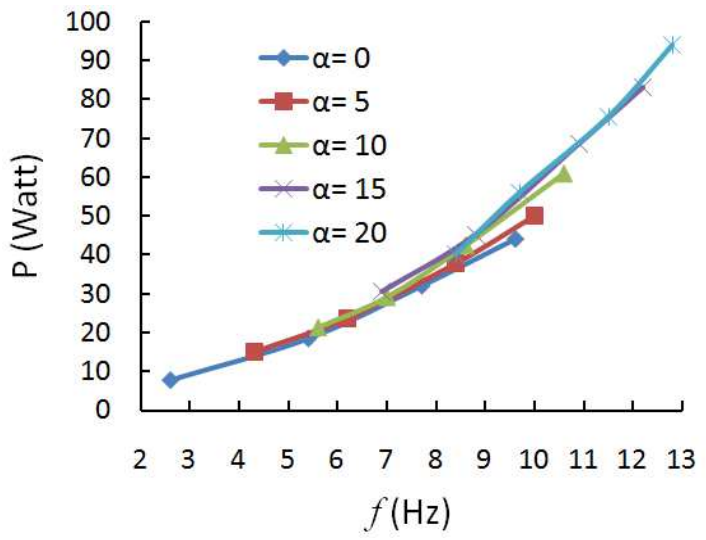

(a)

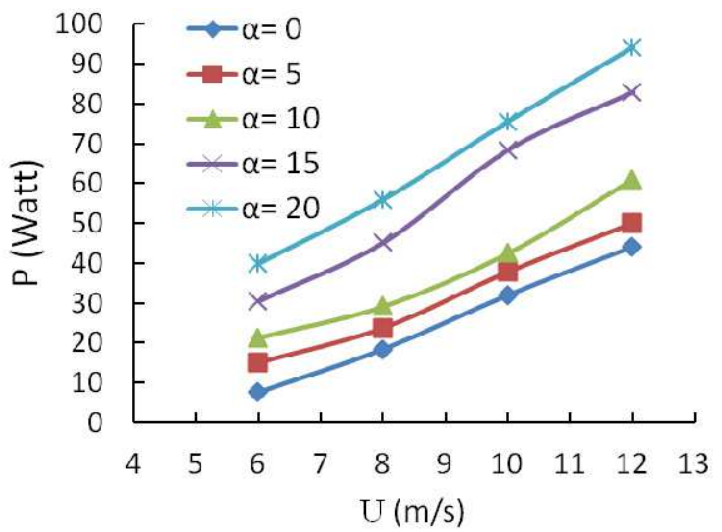

(b)

Fig. 8. The input power as a function of the flapping frequency (cruise flight velocities), for various angles of incidence 


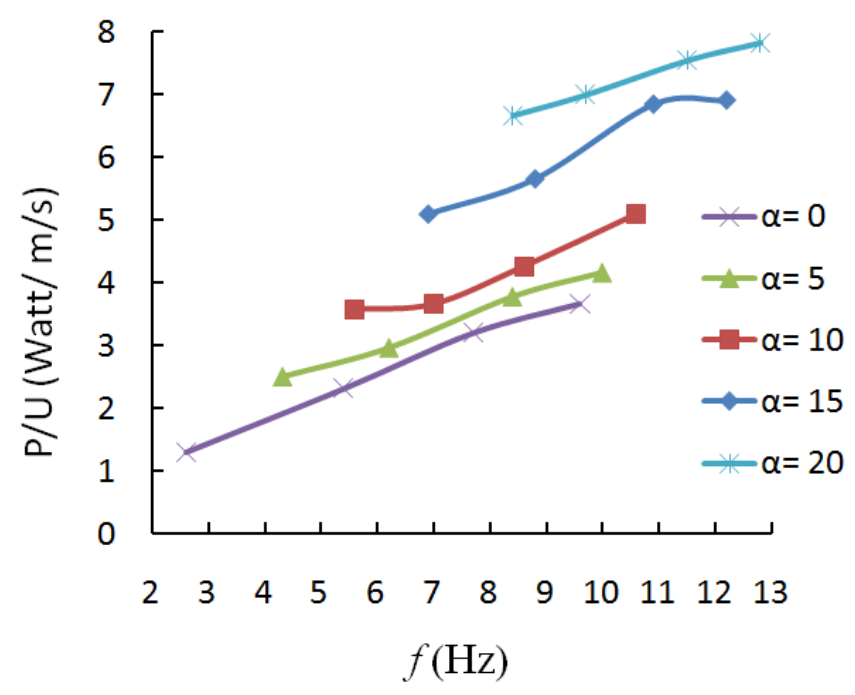

Fig. 9. Energy usage over unit distance as a function of the flapping frequency, for various angles of incidence

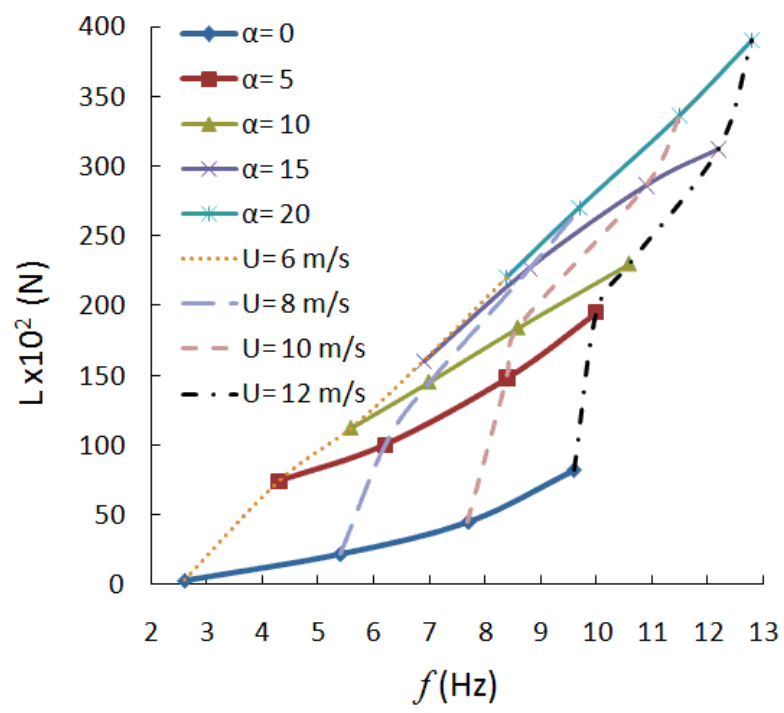

Fig. 10. The average lift as a function of the flapping frequency, for various angles of incidence $\left(L=F\left(f ; \alpha=\alpha_{i}, T=0\right)\right)$, and various cruise speeds $\left(L=F\left(f ; U=U_{i}, T=0\right)\right)$ 


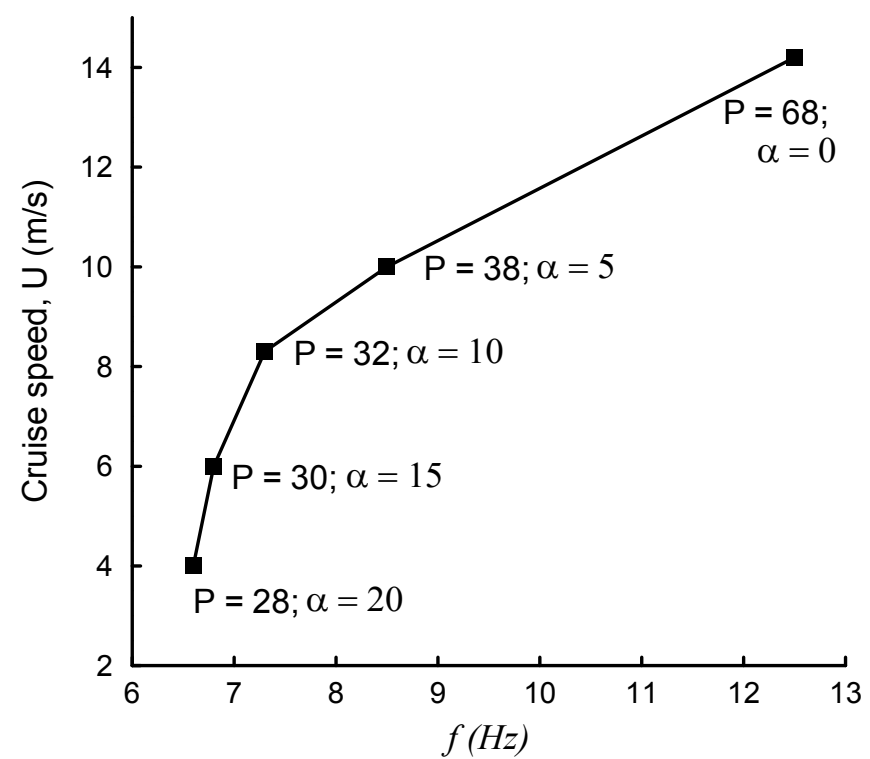

(a)

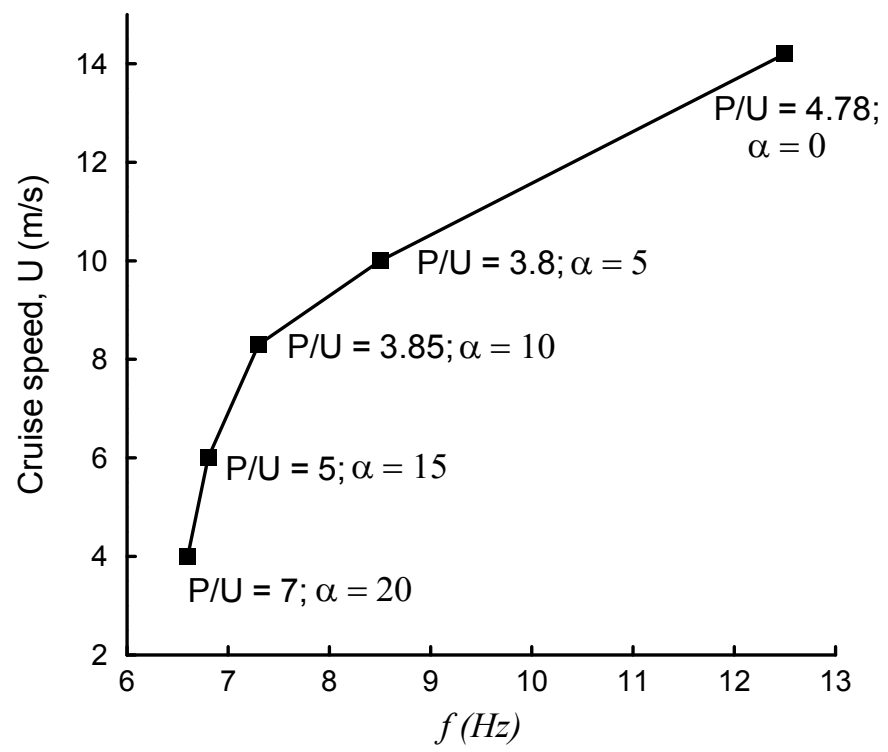

(b)

Fig. 11. Cruise speed versus flapping frequency for $L=W=0.15 \mathrm{~kg}(T=0)$, (a): value of $P$ and $\alpha$ at each point, (b): value of $\frac{P}{U}$ and $\alpha$ at each point 


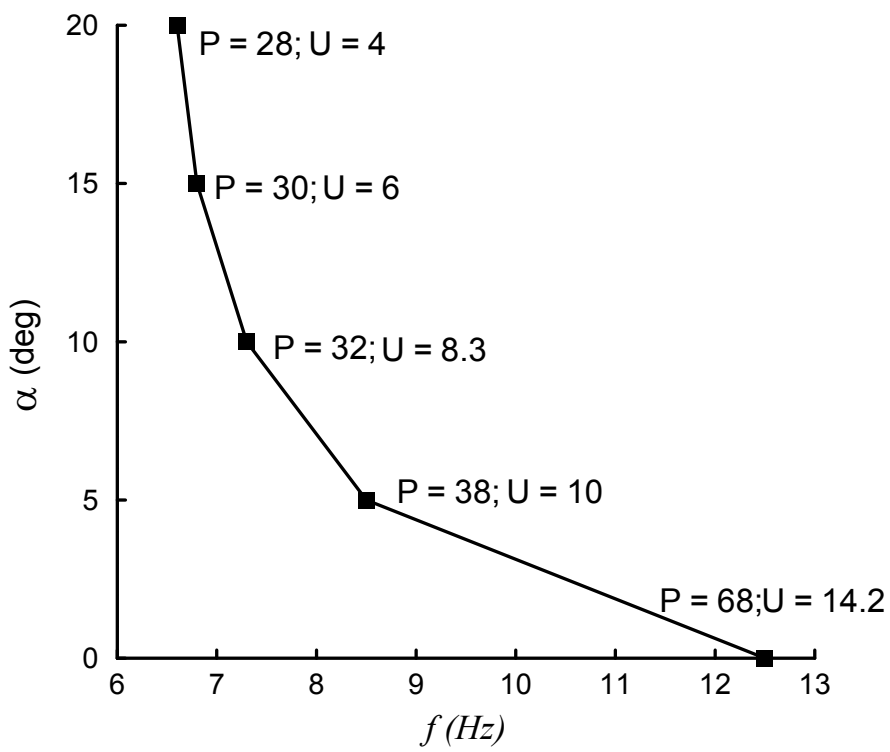

(a)

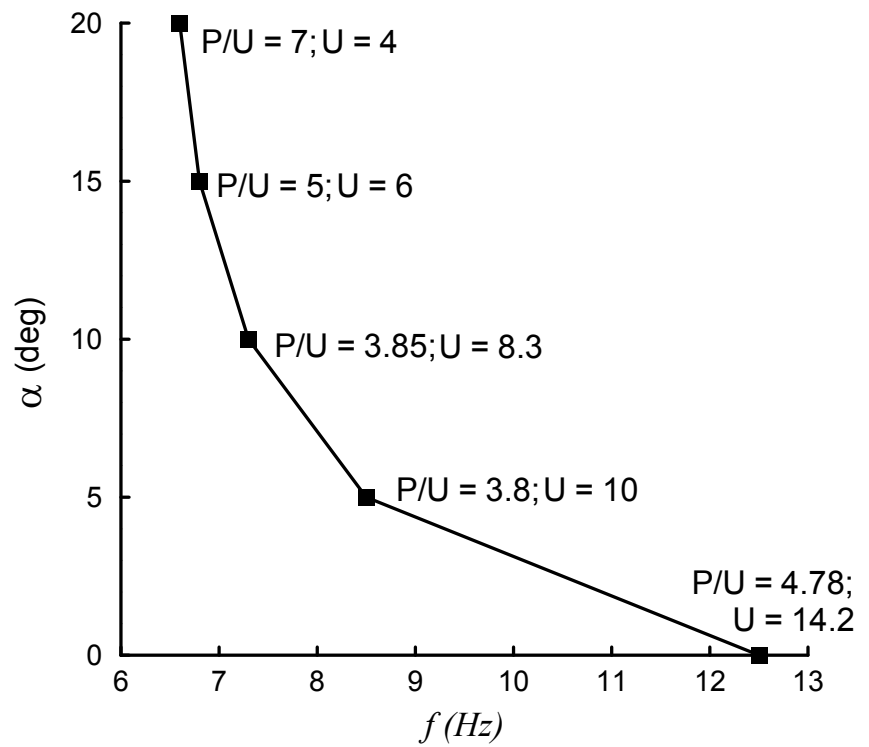

(b)

Fig. 12. Angle of incidence versus flapping frequency for $L=W=0.15 \mathrm{~kg}$ ( $T=0)$, (a): value of $P$ and $U$ at each point, (b): value of $\frac{P}{U}$ and $U$ at each point 
For a given vehicle weight ( $W=0.15 \mathrm{~kg}$ ), these diagrams are shown in Figs. 13 and 14 . As Fig. 13 shows, for the highest endurance, assuming maximum allowable angle of incidence

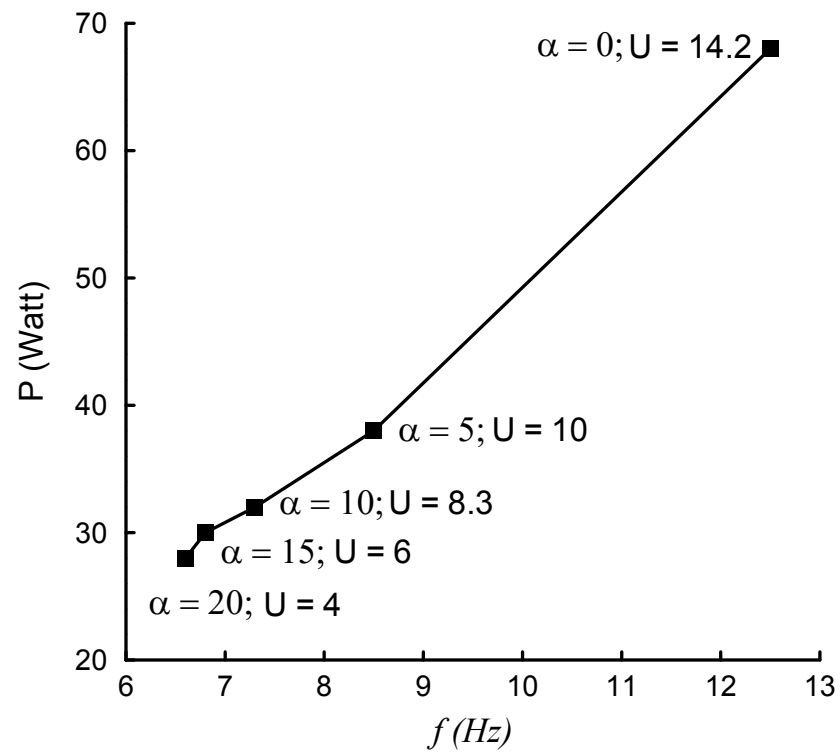

Fig. 13. Power usage versus flapping frequency for $L=W=0.15 \mathrm{~kg}(T=0)$

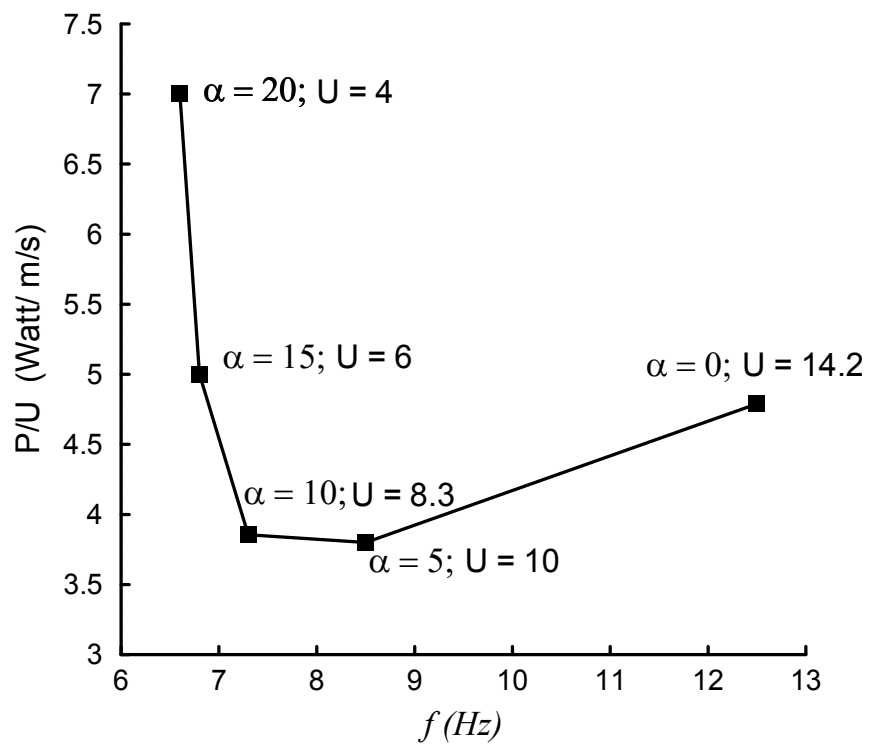

Fig. 14. $\frac{P}{U}$ versus flapping frequency for $L=W=0.15 \mathrm{~kg}(T=0)$ 
equal to $20^{\circ}$, this vehicle may fly by $4.0 \mathrm{~m} / \mathrm{s}$ cruise speed at $20^{\circ}$ angle of incidence. Fig. 14 also shows that for maximum range (minimum $\frac{P}{U}$ ), the vehicle should fly at $8.3 \mathrm{~m} / \mathrm{s}$ with $10^{\circ}$ angle of incidence. Of course these results are correct only for our example wing, but the scheme used here is universal.

As a summary, one may consider two criteria for optimum flight conditions, i.e. flight endurance and range. For each criterion, one may find two flight curves. These curves show optimum flight conditions. Here, we have found only one point of these curves which corresponds to $W$ equal to $0.15 \mathrm{~kg}$. Finding the other points is an easy task, which is not needed here.

\section{Conclusion}

A flapping wing system and an experimental set-up are designed to measure the lift, thrust and power usage of the flapping wing motion for different flapping frequencies, angles of attack and various wind tunnel velocities up to $12 \mathrm{~m} / \mathrm{s}$. Several new parameters are introduced for flapping wings and different criteria are presented for performance analysis. Flight envelopes for a particular flapping vehicle and a new scheme for finding them is introduced. An algorithm is proposed so that for each given mission and vehicle weight (or payload), one may find the best cruise speed, angle of incidence or flapping frequency for maximum range, which is corresponding to minimum ratio of power to cruise speed (i.e,. energy usage for unit distance), or for maximum endurance corresponding to minimum power (i.e., minimum flapping frequency). This scheme allows us to show cruise speed as a function of the flapping frequency, for various angles of incidence, and energy usage over unit distance as a function of the flapping frequency for various angles of incidence. For a special mission with $0.15 \mathrm{~kg}$ weight, the suitable cruise speed versus flapping frequency is demonstrated. The resulting diagrams are used to find optimum performance of the flapping wing vehicle.

\section{Acknowledgment}

Authors acknowledge the support of the Sharif University of Technology and Aerospace Engineering Department.

\section{References}

Aditya, K. \& Malolan, V. (2007). Investigation of Strouhal Number Effect on Flapping Wing Micro Air Vehicle. AIAA Paper 2007-486

Ames, R. (2001). On the Flowfield and Forces Generated by a Rectangular Wing Undergoing Moderate Reduced Frequency Flapping at Low Reynolds Number. Ph.D. Thesis, Georgia Institute of Technology

Daniel, T. \& Combes, S. (2002). Flexing Wings And Fins: Bending By Inertial or Fluid Dynamic Forces? Integrative and Comparative Biology , 42, 1044-1049

Fritz, T. E. \& Long, L. N. (2004). Object-Oriented Unsteady Vortex Lattice Method for Flapping Flight. Journal of Aircraft, 41 (6), 1275-1290 
Gallivan, P. \& DeLaurier, J. (2007). An Experimental Study of Flapping Membrane Wings. Canadian Aeronautics and Space Journal, 53 (2), 35-46

Gebert, G. \& Gallmeier, P. (2002). Equation of Motion for Flapping Flight. AIAA Paper 20024872

Ho, S. (2003). Unsteady Aerodynamics and Adaptive Flow Control of Micro Air Vehicles. Ph.D. Thesis, University of California

Hong, Y. S. \& Altman, A. (2007). Streamwise Vorticity in Simple Mechanical Flapping Wings. Journal of Aircraft, 44 (5), 1588-1597

Isaac, K. Colozza, A. \& Rolwes, J. (2006). Force Measurements on a Flapping and Pitching Wing at Low Reynolds Numbers. AIAA Paper 2006-450

Isogai, K. \& Harino, Y. (2007). Optimum Aeorelastic Design of a Flapping Wing. Journal of Aircraft , 44 (6), 2040-2048

Jones, K. D., Castro, B. M., Mahmoud, O., Pollard, S. J., Platzer, M. F., Gonet, K., et al. (2002). A Collaborative Numerical and Experimental Investigation of Flapping-Wing Propulsion. AIAA Paper 2002-0706

Kim, D. K., Kim, H. I., Han, J. H. \& Kwon, K. J. (2008). Experimental Investigation on the Aerodynamic Characteristics of a Bio-mimetic Flapping Wing with Macro-Fiber Composites. Journal of Intelligent Material Systems and Structures, 19 (3), 423-431

Kim, S., Jang, L., Kim, M. \& Kim, J. (2003). Patent No. US 6,550,716 B1

Lasek, M. \& Sibliski, K. (2003). Analysis of Flight Dynamics and Control of an Entomopter. AIAA Paper 2003-5707

Lin, C. S., Hwu, C. \& Young, W. B. (2006). The Thrust and Lift of an Ornithopter's Membrane Wings with Simple Flapping Motion. Aerospace Science and Technology, $10,111-119$

Mantia, M. L. \& Dabnichki, P. (2009). Unsteady Panel Method for Flapping Foil. Engineering Analysis with Boundary Elements, 33, 572-580

Mazaheri, K. \& Ebrahimi, A. (2010a). Experimental Investigation of the Effect of Chordwise Flexibility on the Aerodynamics of Flapping Wings in Hovering Flight. Journal of Fluids and Structures, 26, 544-558

Mazaheri, K. \& Ebrahimi, A. (2010b). Experimental Study on Interaction of Aerodynamics With Flexible Wings of Flapping Vehicles in Hovering and Cruise Flight. Archive of Applied Mechanics, 80, 1255-1269

Muniappan, A., Baskar, V. \& Duriyanandhan, V. (2005). Lift and Thrust Characteristics of Flapping Wing Micro Air Vehicle (MAV). AIAA paper 2005-1055

Murphy, J. (2008). Experimental Investigation of Biomimetic Wing Configurations for Micro Air Vehicle Applications. Master of Science Thesis, Aerospace Engineering, Iowa State University

Pennycuick, C. J. (2008). Modelling the Flying Bird. Academic Press

Pfeiffer, A. T., Lee, J. S., Han, J. H. \& Baier, H. (2010). Ornithopter Flight Simulation Based on Flexible Multi-Body Dynamics. Journal of Bionic Engineering, 7 (1), 102-111

Shyy, W., Berg, M. \& Ljungqvist, D. (1999). Flapping and Flexible Wings for Biological and Micro Air Vehicles. Progress in Aerospace Science, 35, 455-505

Shyy, W., Lian, Y., Tang, J., Viieru, D. \& Liu, H. (2008). Aerodynamics of Low Reynolds Number Flyers. Cambridge University Press

Singh, B. (2006). Dynamics and Aeroelasticity of Hover-Capable Flapping Wings: Experiments and Analysis. Ph.D. Thesis, University of Maryland 
Smith, M. J., Wilkin, P. J. \& Williams, M. H. (1996). The Advantages of an Unsteady Panel Method in Modelling the Aerodynamic Forces on Rigid Flapping Wings. Journal of Experimental Biology, 199, 1073-1083

Vest, M. S. \& Katz, J. (1996). Unsteady Aerodynamic Model of Flapping Wings. AIAA Journal, 34 (7), 1435-1440

Willis, D. J., Peraire, J., Drela, M. \& White, J. K. (2006). A Numerical Exploration of Parameter Dependence in Power Optimal Flapping Flight. AIAA Paper 2006-2994

Wilson, N. L. \& Wereley, N. (2007). Experimental Investigation of Flapping Wing Performance in Hover. AIAA Paper 2007-1761

Wu, P., Stanford, B. \& Ifju, P. (2008). Structural Deformation Measurements of Anisotropic Flexible Flapping Wings for Micro Air Vehicles. AIAA Paper 2008-1813 


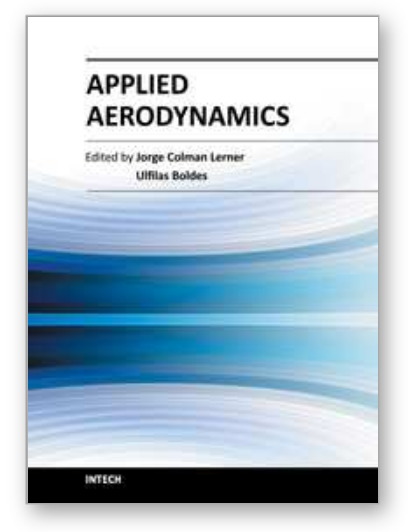

\author{
Applied Aerodynamics \\ Edited by Dr. Jorge Colman Lerner
}

ISBN 978-953-51-0611-1

Hard cover, 192 pages

Publisher InTech

Published online 11, May, 2012

Published in print edition May, 2012

Aerodynamics, from a modern point of view, is a branch of physics that study physical laws and their applications, regarding the displacement of a body into a fluid, such concept could be applied to any body moving in a fluid at rest or any fluid moving around a body at rest. This Book covers a small part of the numerous cases of stationary and non stationary aerodynamics; wave generation and propagation; wind energy; flow control techniques and, also, sports aerodynamics. It's not an undergraduate text but is thought to be useful for those teachers and/or researchers which work in the several branches of applied aerodynamics and/or applied fluid dynamics, from experiments procedures to computational methods.

\title{
How to reference
}

In order to correctly reference this scholarly work, feel free to copy and paste the following:

Abbas Ebrahimi and Karim Mazaheri (2012). Aerodynamic Performance of the Flapping Wing, Applied Aerodynamics, Dr. Jorge Colman Lerner (Ed.), ISBN: 978-953-51-0611-1, InTech, Available from: http://www.intechopen.com/books/applied-aerodynamics/aerodynamic-performance-of-the-flapping-wing

\section{INTECH}

open science | open minds

\section{InTech Europe}

University Campus STeP Ri

Slavka Krautzeka 83/A

51000 Rijeka, Croatia

Phone: +385 (51) 770447

Fax: +385 (51) 686166

www.intechopen.com

\section{InTech China}

Unit 405, Office Block, Hotel Equatorial Shanghai

No.65, Yan An Road (West), Shanghai, 200040, China

中国上海市延安西路65号上海国际贵都大饭店办公楼 405 单元

Phone: +86-21-62489820

Fax: +86-21-62489821 
(C) 2012 The Author(s). Licensee IntechOpen. This is an open access article distributed under the terms of the Creative Commons Attribution 3.0 License, which permits unrestricted use, distribution, and reproduction in any medium, provided the original work is properly cited. 